\title{
The Effect of Mechanical and Geometric Parameters on the Shear and Axial Failures of Columns in Reinforced Concrete Frames
}

\author{
Hooman Farahmand ${ }^{1}$, Mohammad Reza Azadi Kakavand², Shahriar Tavousi \\ Tafreshi ${ }^{3}$, Pooria Hafiz ${ }^{4}$
}

${ }^{1}$ Master candidate, Department of Civil Engineering, Azad University, Dubai, U.A.E. $2 \mathrm{PhD}$ Student, Institute of Structural Mechanics, Faculty of Civil Engineering, Bauhaus University Weimar, Weimar, Germany.

${ }^{3}$ Assistant professor, Department of civil engineering, Azad University of Central Tehran Branch, Tehran, Iran.

${ }^{4}$ Director of Architecture \& Civil Engineering Programs, Azad University, Dubai, U.A.E

\begin{abstract}
Experimental research activities and post-earthquake considerations have demonstrated that reinforced concrete columns with light or widely spaced transverse reinforcement are vulnerable to shear failure during earthquakes. According to this point by using failure limit curve, we can assess the effective parameters in shear and axial failure of reinforced concrete columns in framed buildings. In the current study by flexural, shear and axial springs which are used in series, shear and axial failures and important effective parameters have been assessed, Besides 5,10 and 15 story models with different amounts of initial axial load ratio have been analyzed by nonlinear push-over analysis. The results of analytical models contain behavior of buildings based on different initial axial load ratio and different spacing of transverse reinforcement are compared
\end{abstract}

Keywords: Shear failure, Axial failure, Beam-column element, Uniaxial material model, failure limit curve 


\section{Introduction}

Nowadays, using analytical methods that can identify the types of failure in different modes based on limit-state material elements is inevitable. Thus, to detect the different types of failure in reinforced concrete framed structures, the analytical model is needed in which not only shear and axial failure based on geometric and mechanical specification of columns are detectable but also strength degradation of members in the behavior of modeled buildings will be achieved. The analytical model that is discussed in the current study can identify shear and axial failure of columns based on the drift ratio. The above analytical model, can calculate drift at the time of shear and axial failure occurrence based on limit state of members which itself is affected by the geometric and mechanical characteristics. After shear and axial failure occurrence, mentioned analytical model considers strength degradation of damaged elements based on discussed specification. This means that shear and axial capacity of columns after shear and axial failure will be reduced.The column elements which are used in this paper have flexural, shear and axial mode of failure. Because the results of the analytical model that are used in this paper is only verified for such mode of failure. In this case by using three types of analytical model, 5, 10 and 15 story which all of them include three span, the effects of initial axial load and transverse reinforcement ratios on shear and axial failure have been assessed.

\section{Modeling}

In 2005 the model introduced by Elwood and Moehle relates the shear demand to the drift ratio at shear failure based on the transverse reinforcement and initial axial load ratios. Based on 50 experimental specimens on reinforced concrete columns, flexure failure occurs prior to shear failure as the model defines the drift ratio at shear failure as the drift at which the shear capacity has degraded to $80 \%$ of the maximum measured shear capacity. As shown in Fig. 1, the point of shear failure, according to the model, is determined by the intersection of an idealized bilinear load-deformation curve for the column and the limit surface defined by the drift capacity model. While it is known that the shear strength will degrade after failure, the shape of the load-deformation curve after intersection with the limit surface is not well understood. Experimental research has shown that axial failure of a shear-damaged column due to sliding along inclined shear cracks is related to several variables including the axial stress on the column, the amount of transverse reinforcement, and the drift demand at the point of shear failure. According to Fig. 2, columns with a low axial load or drift demand would not be expected to experience axial failure

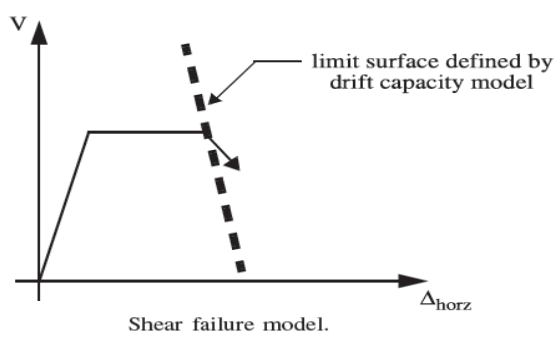

Figure1. shear failure model (Elwood, 2004)

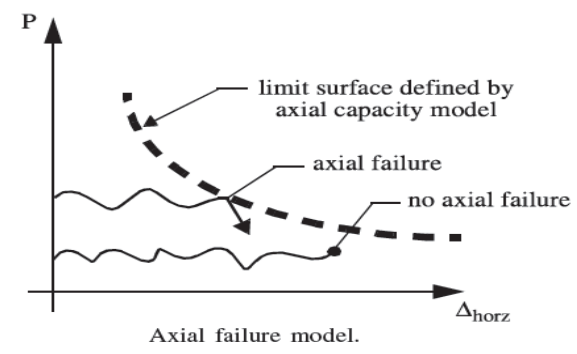

Figure2. Axial failure model (Elwood, 2004)

\subsection{Shear failure investigation of Columns}

To motivate the development of a new uniaxial material model, the example of a shear spring in series with a beam-column element, as shown in Fig. 3, is considered for modeling the shear strength degradation of shear-critical columns. The hysteretic uniaxial material model, with strength degradation, can be used to define the constitutive relationship for the shear spring. For the following discussion it will be assumed that the flexural deformations modelled by the beam-column element include both the deformations due to curvatures over the column height and those due to concentrated rotations at the column ends resulting from anchorage bar slip. . It should be recognized that the series model shown in Fig. 3 simulates the shear response in an average sense over the height 
ofthe column. Intended for the global analysis of a building frame system, this model does not attempt to account for localized deformations over the height of the column. The model in Fig. 3a determines the point of shear failure based only on the column shear. Fig. $3 b$ indicates netresponse of shear spring based on its
stiffness.In Fig. 3c - shear-displacement diagram of beam-column element due to the column shear load is shown. Fig. 3d is related to total response of beam-column element. With the occurrence of shear failure, shear strength of column is reduced. (a)

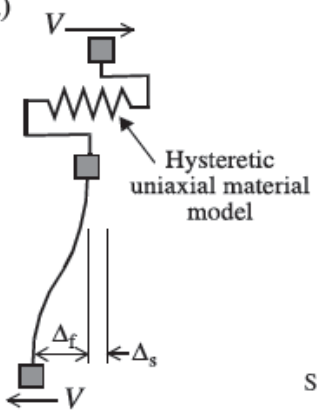

(b)

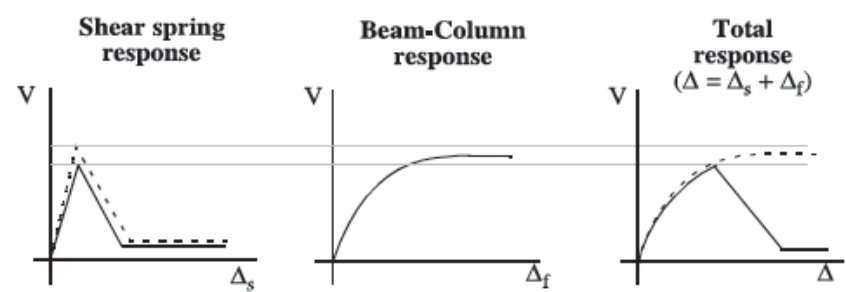

(c)

Shear spring in series model using hysteretic material model.

(d)

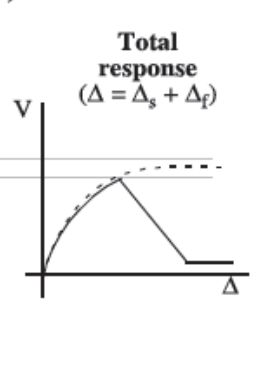

Figure3. Shear spring in series (Elwood, 2004)In this case to define load-deformation equation the limit state material in series by beam-column element is used. Limit state material model indicates response of beam-column element after point of shear failure. If the column after flexural yielding is vulnerable to shear failure, then shear capacity model can be used to define shear limit curve (proposed by Elwood and Moehle) that are shown in equation 1 and 2:

$\left(\frac{\Delta s}{L}\right)=\frac{3}{100}+4 \rho^{\prime \prime}-\frac{1}{40} \frac{V}{\sqrt{f^{\prime} c}}-\frac{1}{40} \frac{P}{A g \cdot f^{\prime} c} \geq \frac{1}{100} \quad(M p a)$

$\left(\frac{\Delta s}{L}\right)=\frac{3}{100}+4 \rho^{\prime \prime}-\frac{1}{500} \frac{V}{\sqrt{f^{\prime} c}}-\frac{1}{40} \frac{P}{A g \cdot f^{\prime} c} \geq \frac{1}{100}$ (psi)

In the given equations $(\Delta \mathrm{s} / \mathrm{L})$ is the drift ratio at shear failure, $Q^{\prime \prime}$ is the transverse reinforcement ratio, $v$ is the nominal shear stress, $\mathrm{f}^{\prime} \mathrm{C}$ is the concrete compressive strength, $\mathrm{P}$ is the axial load on column at shear failure, Ag is the gross cross-sectional area. The backbone before point of failure for the limit state material model is selected as linear with a slope equal to the shear stiffness of an uncracked column. It is important that the shear deformations based on equation 1 and 2 is equal to total displacement of the flexure and shear deformations. As long as the beam-column response intersects the limit curve, the backbone of the shear spring is redefined, as shown in Fig. 4. to include the degrading slope, Kdeg, and residual strength, Fres. Since shear failure will influence the strength of the column in both direction.

After failure occurrence, the response follows the curves shown in Fig. 4. Increase in lateral demands will result in strength degradation of the shear spring and increase on shear deformations, accompanied by unloading of the beam-column element, and thus, a small reduction in the flexural deformations. Experimental results propose that the shear deformations increase after point of shear failure and studies have shown that axial failure tends to occur when the shear strength degrades to approximately zero(Nakamura and Yoshimura 2002). 


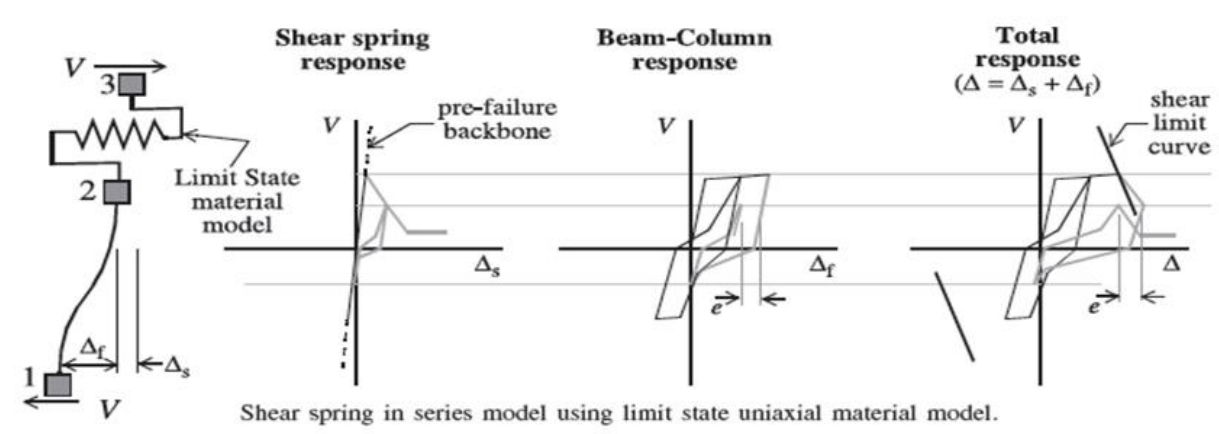

Figure4. Shear spring in series using limit state material model (Elwood, 2004)

Fig. 5. shows the column response model for uniform increase in total displacement. In Case 1, at point of Shear failure the beam-column response has a positive slope, in contrast in Case 2 , a negative slope at shear failure is considerable.

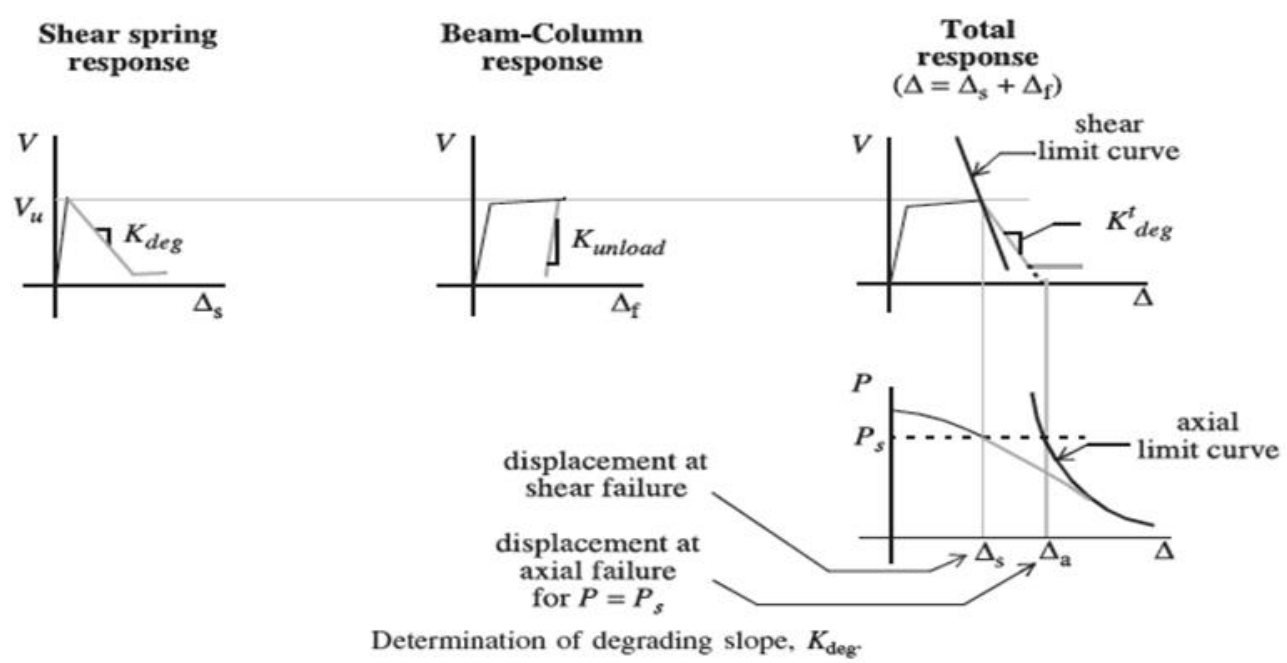

Figure5. Determination of degrading slope , Kdeg, (Elwood, 2004)

\subsection{Axial failure investigation of Columns}

The limit state uniaxial material model can also be used to model axial failure where the limit curve is defined by an axial capacity model for shear-damaged columns (Elwood and Moehle 2003).

$$
\left(\frac{\Delta}{L}\right)_{\text {axial }}=\frac{4}{100} \frac{1+(\tan \theta)^{2}}{\tan \theta+p\left(\frac{s}{A \text { stFstdctan } \theta}\right)}(M p a) \text { or }(p s i)
$$

This model assumes that shear failure has already happened and that axial failure results from sliding along a critical inclined shear crack. In Fig.6. mentioned assumption is shown. The axial capacity model by Elwood and Moehle (2003) suggests that the drift at axial failure, $(\Delta / \mathrm{L})$ axial, is inversely proportional to the axial load supported by the column and directly proportional to the amount of transverse reinforcement where dc is the depth of the column core from center line to center line of the ties, $s$ is the spacing of the transverse reinforcement, Ast and fyt are the area and yield strength of the transverse reinforcement, $\mathrm{P}$ is the axial load on the column, and $\theta$ is the critical crack angle from the horizontal (assumed to be $65^{\circ}$ ).

Fig. 6, indicates that the axial failure limit curve for such column, as defined by the Elwood and Moehle model, can be represented on a plot of total lateral drift versus axial load. After axial failure occurrence the backbone must be redefined that in this step includes degrading slope and Kdeg.

The axial failure model only acceptable for compression failure, therefore backbone is redefined only for compressive axial loads . Shear-axial interaction must be observed in any model in which the behavior after the onset of axial failure is of interest. Experimental studies have indicated that an increase in lateral 
deformation due to shear will cause axial in axial capacity of column. deformation and consequently more dissipation
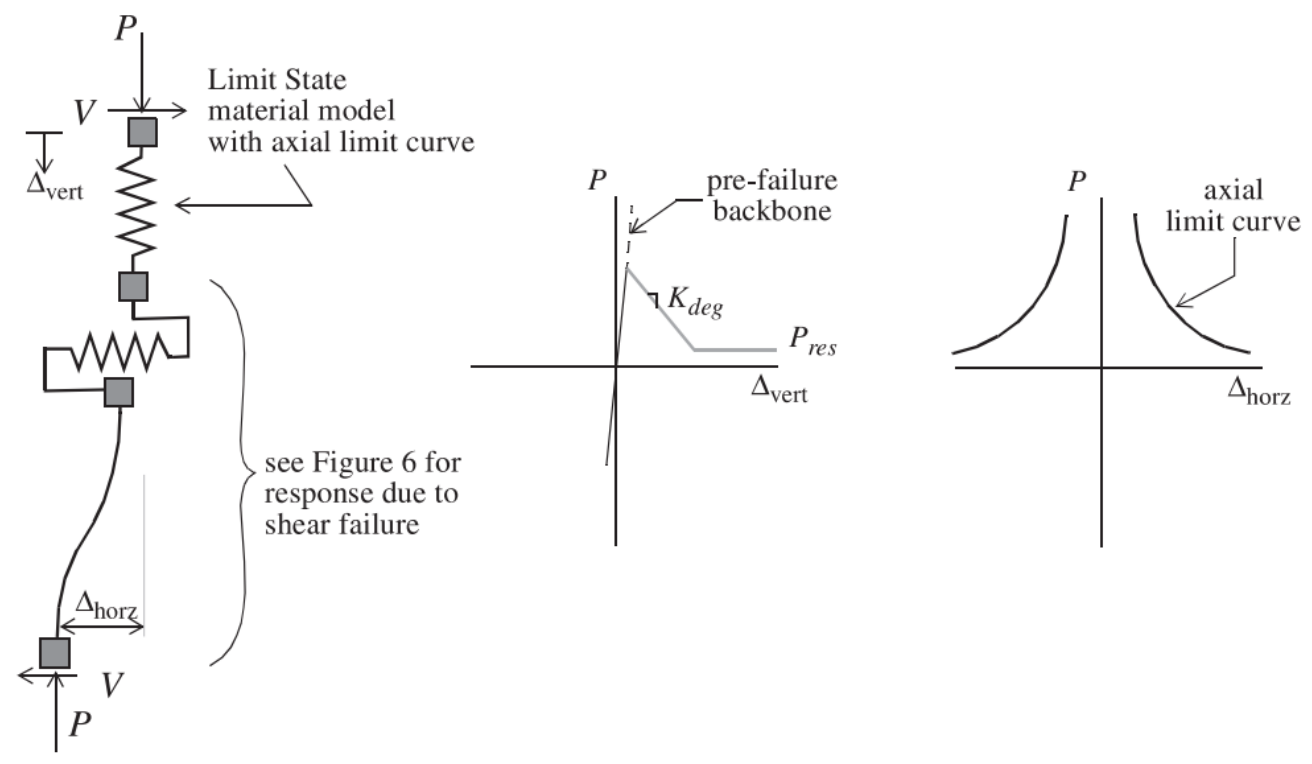

Figure 6. Axial spring in series model (Elwood, 2004)

\subsection{Rotational spring model}

Rotational spring is used at each beam column element end to considering strain of longitudinal reinforcement and its stiffness is Computable based on recommendations of Elwood and Eberhard (2008)equation 4:

$$
K_{\text {slip }}=\frac{8 u}{d b f s} E I_{f l e x} \quad(M p a)
$$

Where, $\mathrm{u}$ is the bond stress (assumed to be 0.8 )(Ref.5), $\mathrm{db}$ is the nominal diameter of the

longitudinal reinforcement, fs is the yield tensile stress in the longitudinal reinforcement, and EIflex is the

effective flexural stiffness. The effective flexural stiffness is calculated from momentcurvature analysis of a column section. For this specific section it is 0.4EIgross, where $\mathrm{E}$ is the concrete modulus of elasticity and Igross is the gross section moment of inertia. In Fig 8.9., a model in which the uniaxial materials and rotational springs have been used, its behavior is defined based on code regulations .

\subsection{Evaluation of failure mode in columns of modeled frames}

In the previous sections, modeling of reinforced concrete frames based on uniaxial materials in existing columns was discussed. In this section modeling based on mentioned principles is discussed.

Based on the available information in provisions, as well as existing previous studies about the failure behavior of columns in existing buildings, columns have three modes of failure: flexure, flexure-shear and shear failure mode. This case regarding $\mathrm{Vp} / \mathrm{Vn}$ ratio for each column is determined. According to the above regulation, Columns with $\mathrm{Vp} / \mathrm{Vn} \leq 0.6$ have flexure mode without any shear failure occurrence, Columns with $0.6<\mathrm{Vp} / \mathrm{Vn} \leq 1$ have shear-flexure-axial mode so that flexural failure is prior to shear failure and shear failure is also prior to axial failure occurred and Columns with $\mathrm{Vp} / \mathrm{Vn}>1$ have shear mode in which shear failure is occurred prior to flexural failure.

In this research amount of $\mathrm{Vp} / \mathrm{Vn}$ in whole columns has been calculated for all 27 models. All columns have shear-flexure-axial mode that it proves flexural, shear and axial springs used in this study are verified based on its assumptions. (equation1,2 and3).

\section{Validation of numerical models compared to experimental models}

\subsection{Experimental}


In this section the results of the numerical model(Opensees) and the results of two-bay two-story reinforced concrete frames that was built at the National Center for Research on Earthquake Engineering (NCREE), Taiwan in 2008-2009, In cooperating with the University of California, Berkeley, will be compared. The main objective of mentioned Experimental research in which 4 two-bay two-story 2D frame on different gravity load and geometric specification are built, is to assess weaknesses of existing building against seismic lateral load.

Since most of the existing buildings are built only based on gravity load and beams are designed more stronger than columns, therefore columns and beam - columns joints are so vulnerable faced to seismic loads and other lateral loads. Thus in this case we have tried to evaluate the columns with characteristic of existing building.

Based on this principle and specification of the 7 story hospital in Taiwan 4 mentioned model have been tested on shake table. In this section details of one of the four model and relevant damages will be discussed(Table-1). Also to assess validity and compatibility of the numerical model and its rotational, shear and axial springs with experimental results, a model with shear-flexureaxial mode was chosen. Based on geometric and mechanical specification and loading method of described frame, numerical modeling of nonlinear static and dynamic analysis has been implemented on it. The results of numerical modeling and laboratory results are given at the end of this section. Figure 7 indicates considered frame in verification section.

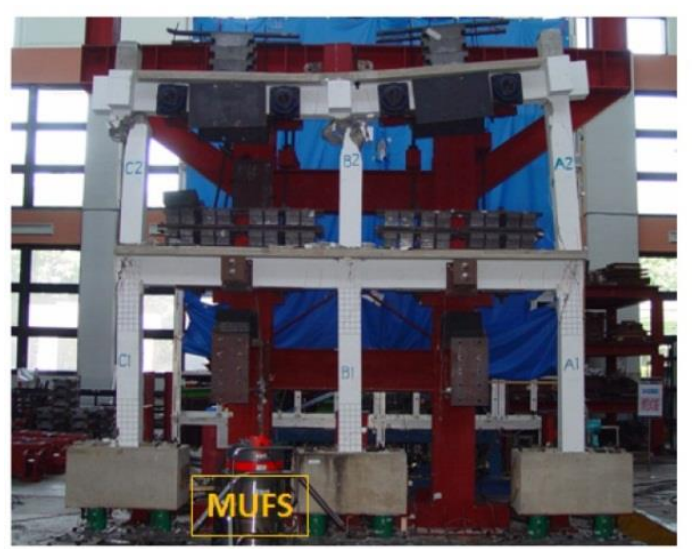

Figure7. Experimental Model (Elwood, 2008)

In above laboratory model net height of columns and net length of beams are 140 and 180 $\mathrm{cm}$ respectively and the amount of longitudinal and transverse reinforcement of column are 2.6 and $0.16 \%$.(table 1$)$.

Table 1. Mechanical and geometric characteristic of laboratory model

\begin{tabular}{|c|c|c|c|c|c|c|c|}
\hline $\begin{array}{l}\text { Type of } \\
\text { Element }\end{array}$ & Story & $\begin{array}{l}\text { Dimension } \\
(\mathrm{cm})\end{array}$ & $\begin{array}{l}\text { Amount } \\
\text { Of Transsverse } \\
\text { Reinforcement }\end{array}$ & $\begin{array}{c}\text { Spacing } \\
\text { Of Transsverse } \\
\text { Reinforcement }(\mathrm{cm})\end{array}$ & $\begin{array}{c}f_{C} \\
(\mathrm{MPa})\end{array}$ & $f_{Y}(\mathrm{MPa})$ & $\begin{array}{c}f_{Y S} \\
(\mathrm{MPa})\end{array}$ \\
\hline Column & $2-1$ & $20 \times 20$ & $8 \# 4$ & \#5 @ 12 & \multirow{3}{*}{28} & \multirow{3}{*}{444} & \multirow{3}{*}{417} \\
\hline \multirow[b]{2}{*}{ Beam } & 1 & $20 \times 30$ & $8 \# 5$ & \multirow[b]{2}{*}{ \#3@15 } & & & \\
\hline & 2 & $20 \times 30$ & $\begin{array}{l}4 \# 4 \\
4 \# 3\end{array}$ & & & & \\
\hline
\end{tabular}

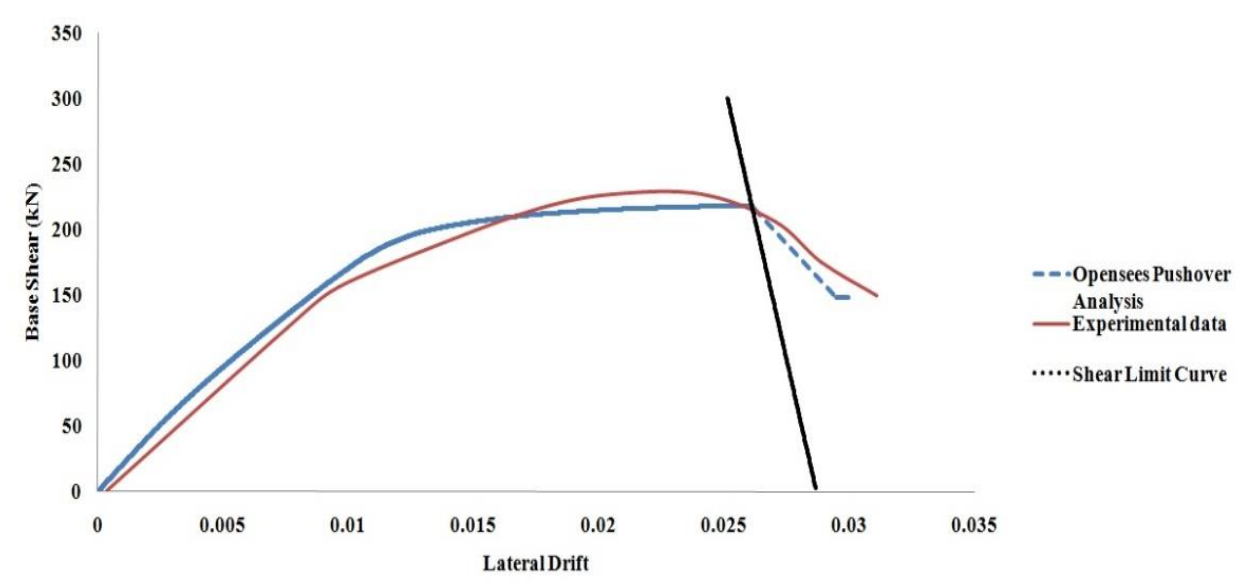

Figure 8. Comparison the results of numerical Pushover modeling and experimental test for first floor 


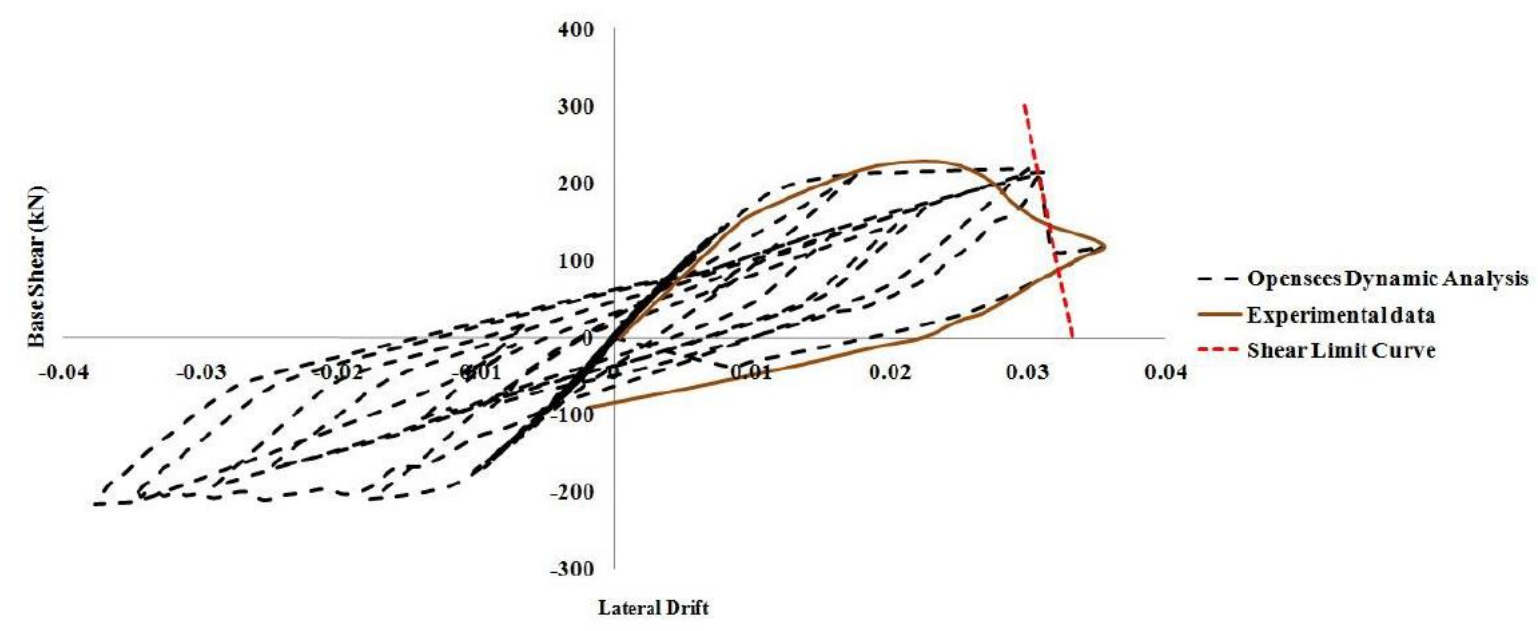

Figure9. Comparison the results of numerical time history modeling and experimental test for1st floor

\subsection{Comparison the results of push- over and time history analysis on numerical and experimental models}

The experimental model which is used for verification based on acceleration equal $1.1 \mathrm{~g}$ due to record of Chi Chi1 earthquake in Taiwan (1999) was located on shake table in laboratory. During testing shear cracks were observed along column element so that centralization and expansion of large cracks in the top of columns, reduced frame stiffness therefore the model was not collapsed .Also drift ratio in the first and second story were 3 and $2.1 \%$ respectively that this can be due to lack of columns confinement.As a result large deformation capacity is created. Although columns in the second story have not experienced shear failure but, shear failure is occurred in side columns of the first story.

Results illustrated that drift in middle columns have not good agreement with drift capacity of flexure - shear frames at the point of shear failure because, in shear failure occurrence rotation of end point of column element has significant role instead drift of column element. In table 2 results of experimental and numerical analysis(Time history-Push over) have been shown.

Figure 8 and 9 show the results of numerical and experimental analysis.
Table 2. Results of numerical and experimental models

\begin{tabular}{c|c|cc}
\hline $\begin{array}{c}\text { Type of } \\
\text { model }\end{array}$ & $\begin{array}{c}\text { Type of } \\
\text { analyze }\end{array}$ & $\begin{array}{c}\text { Max base } \\
\text { shear } \\
(\mathrm{KN})\end{array}$ & $\begin{array}{c}\text { Drift at the } \\
\text { Point of first } \\
\text { Shear failure }\end{array}$ \\
\hline Laboratory & $\begin{array}{c}\text { Nonlinear } \\
\text { Time history }\end{array}$ & 227.02 & 2.41 \\
\hline Numerical & $\begin{array}{c}\text { Nonlinear } \\
\text { Time history }\end{array}$ & 218.75 & 3.00 \\
\cline { 2 - 4 } & $\begin{array}{c}\text { Nonlinear } \\
\text { Push over }\end{array}$ & 218.25 & 2.85 \\
\hline
\end{tabular}

Table 2 and Fig 8 indicates that base shear at the first floor in numerical nonlinear static model is $218.25(\mathrm{KN})$, While base shear in laboratory test is reported $227.02(\mathrm{KN})$,it means there is 4.02 $\%$ difference between them. But the amount of shear drift at the point of shear failure in numerical model is $2.58 \%$ and for laboratory test is reported $2.41 \%$, this means that $7.05 \%$ difference is existed for side column. This comparison showed that results have low difference with each other and good compatibility is reached. Based on Table 2 and Fig 9 base shear at the first floor in numerical nonlinear time history model is $218.75(\mathrm{KN})$ and in laboratory test is reported $227.02(\mathrm{KN}), 3.78 \%$ difference is existed.

In other hands shear drift at the point of shear failure in numerical model is $3 \%$ and $2.41 \%$ for laboratory test is reported in which, $19.67 \%$ difference is achieved that it is less than existing difference in nonlinear static model. By investigation in results, it is found that base 
shear in numerical nonlinear static model and numerical nonlinear time history model have good agreement.

\section{Results of nonlinear static push- over for models with flexural - shear and axial springs}

According to flexure - shear and axial springs model that are in series , 5,10 and 15 story 2 bay2D frame models have been analyzed by Non- linear static (pushover) based on maximum roof displacement equal $10 \%$ of building's height, in a triangular shape of lateral loading. The results of shear and axial failure occurrence for all 27 model with more data have been detected based on uniaxial material models that in the following sections will be provided separately. In figures 10 and 11 details of the 5 story building and its specifications are accessible. Details of flexure shear and axial springs model which are used in all 27 models is shown in Figure12.

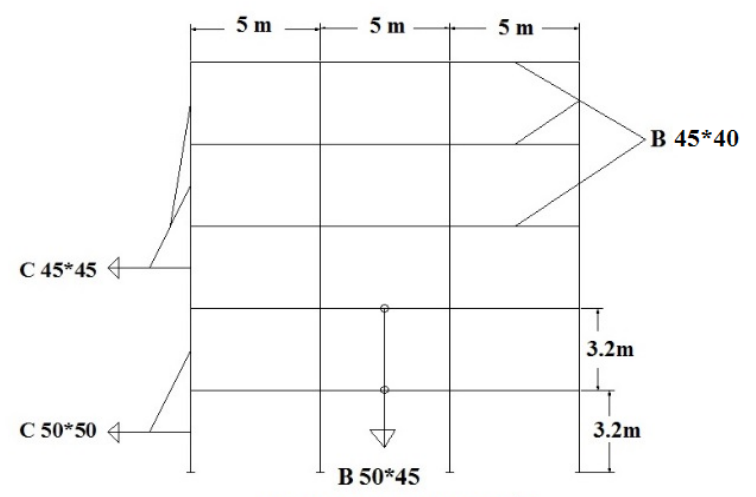

Figure 10. Beam and column dimensions for the 5 story model

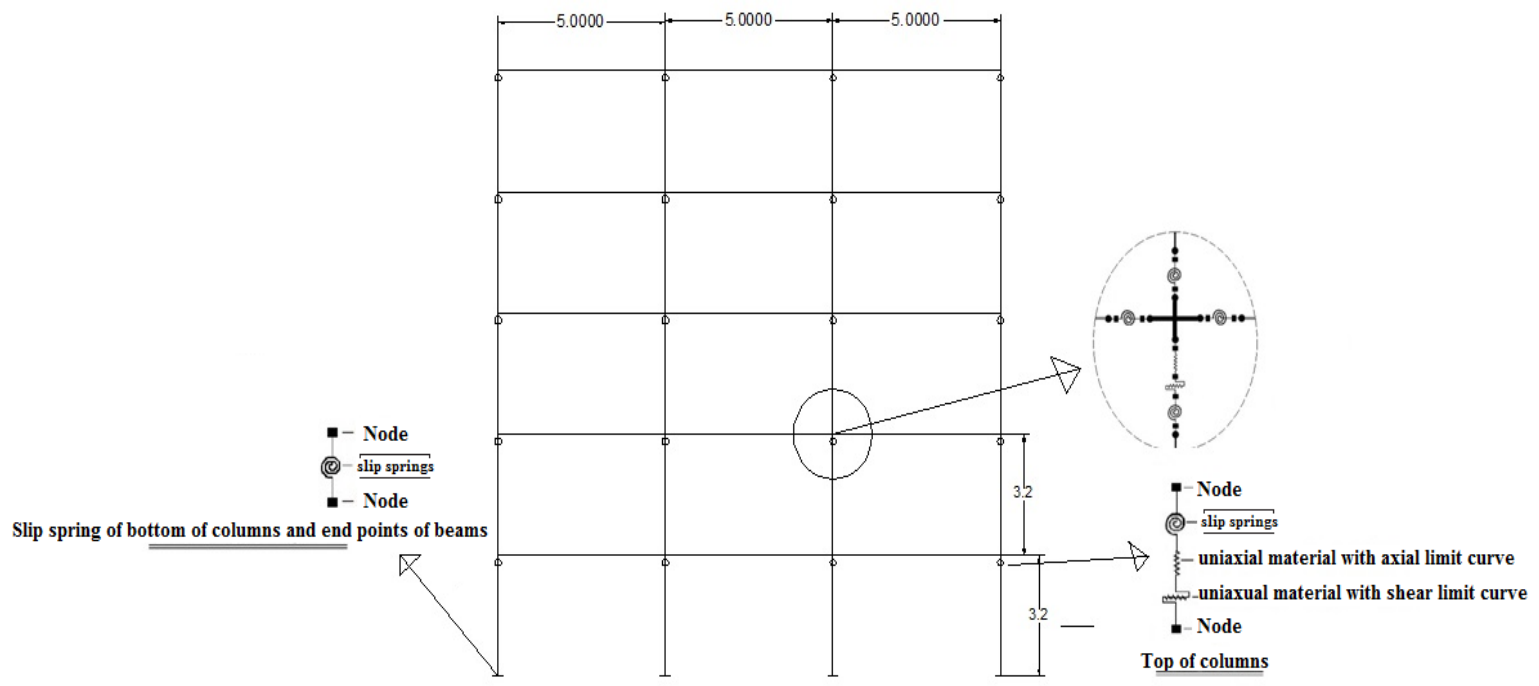

Figure 11. Springs model of joints 


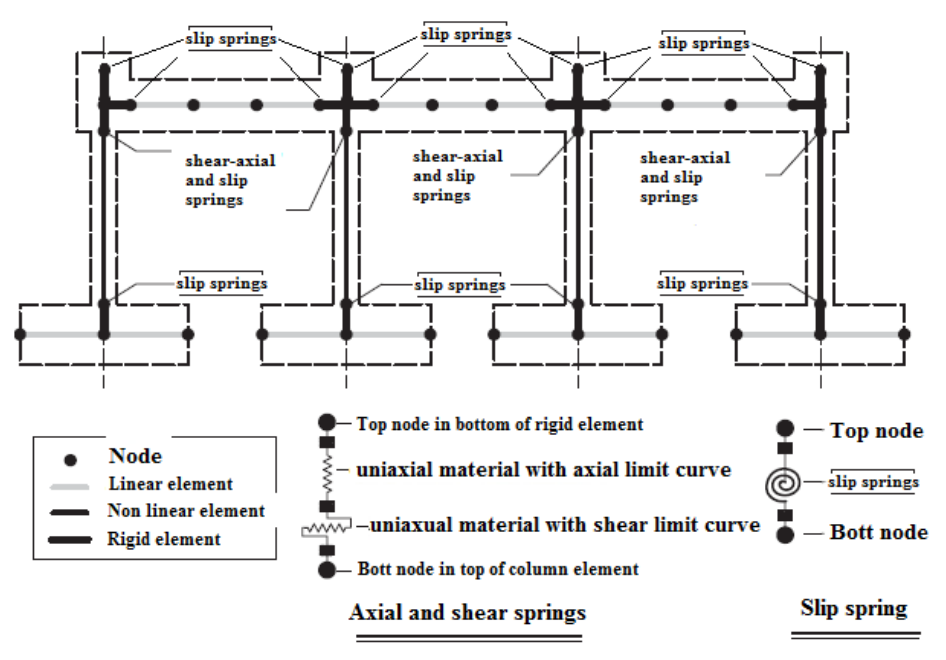

Figure 12. Details of flexural - shear and axial springs (Elwood, 2004)

In table 3 geometric and characteristics of other models are shown. As it is shown in table 3, mechanical and geometric characteristic of all 27 numerical models are based on existing and common Residential and commercial buildings in Iran.

Table 3. Mechanical and geometric characteristic of numerical model

\begin{tabular}{|c|c|c|c|c|}
\hline Model & $\begin{array}{c}\text { Type } \\
\text { Of Element }\end{array}$ & Story & $\begin{array}{l}\text { Dimension } \\
\quad(\mathrm{cm})\end{array}$ & $\begin{array}{l}\text { Amount } \\
\text { Of Transverse } \\
\text { Reinforcement }\end{array}$ \\
\hline \multirow{4}{*}{5 story } & \multirow{2}{*}{ Column } & $2-1$ & $50 \times 50$ & $8 \Phi 30$ \\
\hline & & $5-4-3$ & $45 \times 45$ & $8 \Phi 28$ \\
\hline & \multirow{2}{*}{ Beam } & $2-1$ & $50 \times 45$ & $8 \Phi 28$ \\
\hline & & $5-4-3$ & $45 \times 40$ & $8 \Phi 24$ \\
\hline \multirow{6}{*}{ 10story } & \multirow{3}{*}{ Column } & $3-2-1$ & $55 \times 55$ & $8 \Phi 32$ \\
\hline & & 6-5-4 & $50 \times 50$ & $8 \Phi 30$ \\
\hline & & $10-9-8-7$ & $45 \times 45$ & $8 \Phi 28$ \\
\hline & \multirow{3}{*}{ Beam } & $3-2-1$ & $55 \times 50$ & $8 \Phi 30$ \\
\hline & & $6-5-4$ & $50 \times 45$ & $8 \Phi 28$ \\
\hline & & $10-9-8-7$ & $45 \times 40$ & $8 \Phi 24$ \\
\hline \multirow{8}{*}{15 story } & \multirow{4}{*}{ Column } & $3-2-1$ & $60 \times 60$ & $8 \Phi 36$ \\
\hline & & $7-6-5-4$ & $55 \times 55$ & $8 \Phi 32$ \\
\hline & & $11-10-9-8$ & $50 \times 50$ & $8 \Phi 30$ \\
\hline & & 15-14-13-12 & $45 \times 45$ & $8 \Phi 28$ \\
\hline & \multirow{4}{*}{ Beam } & $3-2-1$ & $60 \times 55$ & $10 \Phi 30$ \\
\hline & & $7-6-5-4$ & $55 \times 50$ & $8 \Phi 30$ \\
\hline & & $11-10-9-8$ & $50 \times 45$ & $8 \Phi 28$ \\
\hline & & $15-14-13-12$ & $45 \times 40$ & $8 \Phi 24$ \\
\hline
\end{tabular}

\subsection{Results of nonlinear static push over on 3 bay- 5 story models}

The 5 story models consist three types of axial load proportion and transverse reinforcement. Totally all of nine mentioned models in terms of drift capacity at the point of shear and axial failure in column element have been evaluated. In this study occurrence of described destructions due to general behavior of building are assessed. In table 4 results of mentioned evaluation have been collected. 
Table 4. Results of non linear push-over analysis on 5 story models

\begin{tabular}{c|cccc}
\hline $\begin{array}{c}\text { P/A } \\
\text { g.f'c }\end{array}$ & $\begin{array}{c}\text { Spacing Of } \\
\text { Transverse } \\
\text { Reinforcement }(\mathrm{cm})\end{array}$ & $\begin{array}{c}\text { Max base shear } \\
(\mathrm{KN})\end{array}$ & $\begin{array}{c}\text { Drift at the } \\
\text { First } \\
\text { shear } \\
\text { Failure } \%\end{array}$ & $\begin{array}{c}\text { Drift at the } \\
\text { First } \\
\text { axial Failure } \\
\%\end{array}$ \\
\hline \multirow{3}{*}{0.25} & 25 & 878.9 & 2.28 & 2.30 \\
& 20 & 927.8 & 2.46 & 2.48 \\
& 15 & 990.36 & 2.75 & 2.75 \\
\hline 0.17 & 25 & 944.8 & 2.43 & 2.44 \\
& 20 & 952.3 & 2.54 & 2.56 \\
0.12 & 15 & 991 & 2.80 & 2.81 \\
& 25 & 940.6 & 2.41 & 2.43 \\
& 20 & 964.3 & 2.56 & 2.60 \\
\hline
\end{tabular}

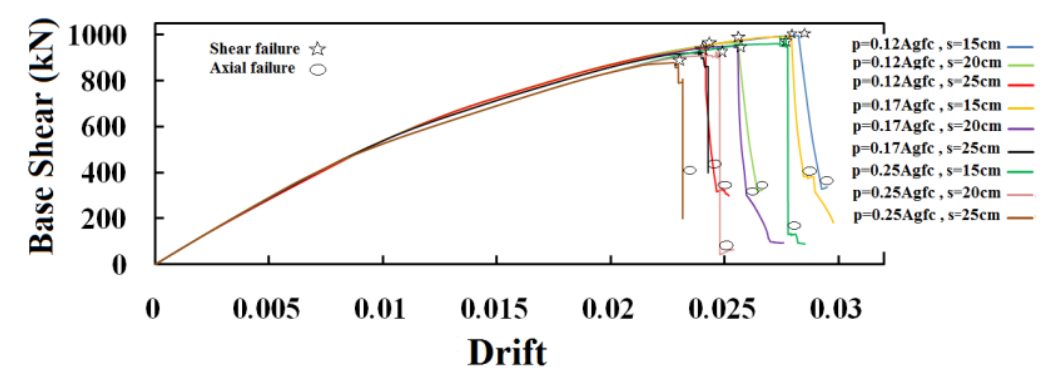

Figure 13. Roof drift vs base shear - 5Story

As it has been illustrated in table 4 , due to increase of initial axial load proportion and spacing of transverse reinforcement in columns, not only capacity of lateral deformation reduced, but also in lower ratio of drift, shear and axial failures are detected.

As it is described differences between point of shear and axial failure in models with axial ratio and spacing of transverse bars equal to 0.25 and $25 \mathrm{~cm}$ compared with the model in which axial ratio and spacing of transverse bars are 0.12 and $15 \mathrm{~cm}$ were found $23.68 \%$ and $24.78 \%$ respectively. Roof drift diagrams versus base shear are located in figure 13.In this graph exact point of the first shear and axial failure occurrence are determined.Clearly gravity loads and transverse bars play significant role to determine flexibility of columns.

\subsection{Results of nonlinear static push over on 3bay-10 story models}

In this section 10 story models that have experienced nonlinear analysis with different loading and transverse bars will be assessed .Relevant data are available in table 5 and figure 14.

As it is shown in table 5 similar 5-story models increase in initial axial load proportion and spacing of transverse reinforcement in columns, makes reduction in capacity of lateral deformation, also lower ratio of drift, at the point of shear and axial failures are achieved.

As it is shown in table 5 similar 5-story models increase in initial axial load proportion and spacing of transverse reinforcement in columns, makes reduction in capacity of lateral deformation, also lower ratio of drift, at the point of shear and axial failures are achieved.

Exact point of the first axial and shear failure occurrence in 10 story frames have drawn in figure 14. In models with ratio of axial load equal 0.12 and spacing of transverse reinforcement equal 15 and $20 \mathrm{~cm}$, axial failure is not occurred. 
Table 5. Results of non linear push-over analysis on 10 story models

\begin{tabular}{c|cccc}
\hline $\begin{array}{c}\text { P/A } \\
\text { g.f'c }\end{array}$ & $\begin{array}{c}\text { Spacing } \\
\text { Transverse } \\
\text { Reinforcement } \\
(\mathrm{cm})\end{array}$ & $\begin{array}{c}\text { Max base shear } \\
(\mathrm{KN})\end{array}$ & $\begin{array}{c}\text { Drift at the } \\
\text { First } \\
\text { shear } \\
\text { Failure } \%\end{array}$ & $\begin{array}{c}\text { Drift at the } \\
\text { First } \\
\text { axial Failure } \\
\%\end{array}$ \\
\hline \multirow{3}{*}{0.25} & 25 & 784.13 & 1.66 & 1.66 \\
& 20 & 816.64 & 1.89 & 1.89 \\
\hline \multirow{3}{*}{0.17} & 15 & 866.61 & 2.18 & 2.19 \\
\hline \multirow{3}{*}{0.12} & 25 & 894.51 & 1.98 & 1.99 \\
& 20 & 926.16 & 2.1 & 2.13 \\
& 15 & 964.83 & 2.29 & 2.34 \\
\hline & 25 & 959.75 & 2.07 & 2.1 \\
\hline
\end{tabular}

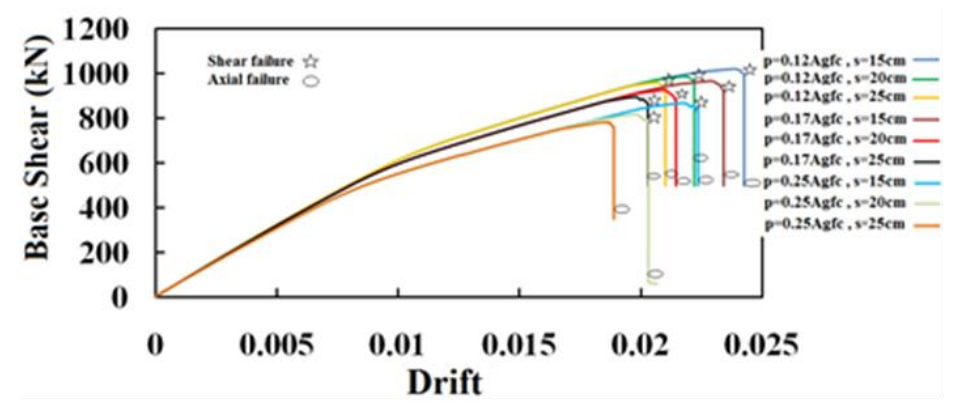

Figure 14. Roof drift s base shear - 10 Story

Model with 0.25 ratio of axial load have less drift capacity and due to bigger amount of axial load more number of shear failures are detected in such columns. therefore shear capacity of model has decreased significantly and structure has arrived in unstable situation, thus analyze has been stopped.

\subsection{Results of nonlinear static push over on 3bay-15 story models}

In this section 15 story models that have similar characteristic with other model in terms of initial axial load proportion and spacing of transverse reinforcement in columns will be discussed. Results have been collected in table 6 and figure 15. Clearly table 6 indicates that similar 5and 10-story models increase in initial axial load proportion and spacing of transverse reinforcement in columns, makes reduction in capacity of lateral deformation, also lower ratio of drift, at the point of shear and axial failures are achieved.

As it is described differences between point of shear failure in models with axial ratio and spacing of transverse bars equal to 0.25 and 25 $\mathrm{cm}$ compared with the model in which axial ratio and spacing of transverse bars are 0.12 and $15 \mathrm{~cm}$ were found $42.91 \%$. Exact point of the first axial and shear failure occurrence in 15 story frames have drawn in figure 15and allowed us to compare between models concerning effects of axial and shear failure occurrence on the structural behavior.

As it is shown in table 6 and figure 15, in some models, axial and shear failure occurs at the same time. The reason of this matter is sudden and significant reduction of lateral capacity of column element after point of shear failure. So that the compressive axial force displacement curve intersects axial failure limit curve and based on relevant drift axial failure is recognized. 


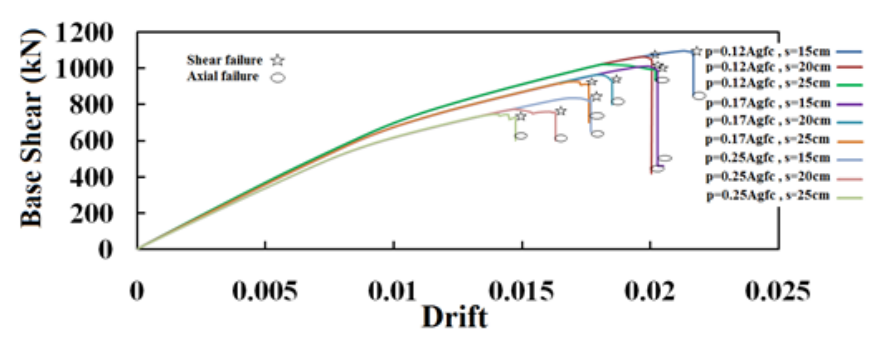

Figure 15. Roof drift vs base shear - 15 Story

Table 6. Results of non linear push-over analysis on 15 story models

\begin{tabular}{c|cccc}
\hline \multirow{2}{*}{ P/Ag.f'c } & $\begin{array}{c}\text { Spacing Of Transverse } \\
\text { Reinforcement }(\mathrm{cm})\end{array}$ & Max base shear (KN) & $\begin{array}{c}\text { Drift at the First } \\
\text { shear Failure \% }\end{array}$ & $\begin{array}{l}\text { Drift at the } \\
\text { First } \\
\text { axial Failure \% }\end{array}$ \\
\hline \multirow{3}{*}{$0 / 25$} & 25 & 744.11 & 1.216 & 1.216 \\
& 20 & 774.95 & 1.436 & 1.436 \\
\hline \multirow{3}{*}{$0 / 17$} & 15 & 839.44 & 1.695 & 1.695 \\
\hline \multirow{3}{*}{$0 / 12$} & 25 & 926.098 & 1.63 & 1.63 \\
& 20 & 962.696 & 1.803 & 1.807 \\
& 15 & 1012.43 & 1.991 & 2.009 \\
\hline
\end{tabular}

\section{Conclusion}

In this study, at the first a model whit its flexure, shear and axial springs behavior in opensees was discussed, the application of described springs in this paper is considered. Besides, results of nonlinear- push over analyze on 5-10 and 15 story models under various scenarios of initial proportion of axial load and spacing of transverse reinforcement in columns have been evaluated. Results indicates that all 5and 15 story model have experienced shear and axial failure so that applied model could consider the effect of initial proportion of axial load and spacing of transverse reinforcement on the amount of lateral capacity at the point of axial and shear failure occurrence. Two models of 10 story models axial failure is not reported because, in most of columns shear failure is happened and large amount of lateral displacement made instability in structure therefore, before axial failure would be occurred structure had been collapsed and axial failure was not detected and we can consider the point of shear and axial failure in the same time. Generally with applying uniaxial material model engineers can evaluate the column elements behavior and structural behavior in terms of capacity of lateral displacement .Clearly the importance of these studies are in structural design, estimate its ductility during earthquakes, as well as a economical design.

\section{References}

Azadi Kakavand, M.R. (2012). Assessment of the numerical modeling of shear and axial failure in existing reinforced concrete framed buildings due to earthquake. Thesis for the degree of Master of Science in Structural Engineering.

Elwood, K.J., and Moehle, J.P. (2003). Shake table tests and analyticalstudies on the gravity load collapse of reinforced concreteframes. Pacific Earthquake Engineering Research Center, Universityof California, Berkeley, California. PEER Report.

Elwood, K.J., and Moehle, J.P. (2005). Drift capacity of reinforced concrete columns with light transverse reinforcement. Earthquake Spectra.

Azadi Kakavand, M.R. (2012) Limit state material manual, Available on www.Opensees.berkeley.edu, University of California, Berkeley. 
Elwood K.J. (2004) Modelling failures in existing reinforced concrete columns, Department of Civil Engineering, The University of British Columbia, 6250 Applied Science Lane, Vancouver, BC V6T 1Z4, Canada.

Yavari S, Elwood K.J, et al. (2012). Study on collapse of flexure-shear-critical reinforced concrete frames, Department of Civil Engineering, Tsinghua University, Beijing, China; in: the 11th World Conference on Earthquake Engineering, Beijing, China.

Elwood K.J, et al. (et al) Update to ASCE/SEI 41 Concrete Provisions.

KhanMohammadi, M., Azadi Kakavand, M.R. (2011). The assessment of the approach of provisions on shear and axial failure in reinforced concrete Columns. 6th National Conference on Civil Engineering, Semnan, Iran.

Azadi Kakavand, M.R, et al. (2010). The Presentation of Solutions to Prevent shear and axial failure in Reinforced Concrete Columns. 2nd National Conference on Concrete, Tehran, Iran.

OpenSEES. Open System for Earthquake Engineering Simulation. (2008). Pacific Earthquake Engineering Research Centre, University of California. http://www.opensees.berkeley.edu.

Yavari S, Elwood K.J, et al. (2009). Design of dynamic collapse testing system for 2storyreinforced concrete frames, National Center for Research on Earthquake Engineering, Taipei, Taiwan.

Elwood K.J, Moehle J.P. (2004) An Axial Capacity Model for Shear-Damaged Columns, Pacific Earthquake Engineering Research (PEER), University of California, Berkeley.

Moehle J.P, Elwood K.J, Sezen H. (2002). Cyclic shear and axial strength of lightly-confined concrete columns, Pacific Earthquake Engineering Research (PEER), University of California, Berkeley.

Elwood K.J, Moehle J.P. (2004). Evaluation of existing reinforced concrete columns, 13th World Conference on Earthquake Engineering, Vancouver, B.C, Canada.
KhanMohammadi M., Azadi Kakavand, M.R. (2013). Analytical comparison of occurring shear and axial failure in existing reinforced concrete columns with ASCE/SEI41-07 provision under Non-Linear static analysis. International Conference on Civil Engineering Architecture \& Urban Sustainable Development, Tabriz, Iran. 